\title{
Development of inter-particle friction in a railway ballast
}

\author{
C. P. Y. WONG* and M. R. COOP*
}

\begin{abstract}
A detailed experimental programme investigated how the coefficient of friction at particle contacts for a typical UK railway ballast varied during cyclic loading. Despite a decrease of roughness, the friction coefficient increased steadily, stabilising in the region of tens of cycles. In contrast to previous work on the contact behaviour of sands, water inundation caused a significant but reversible decrease of the coefficient, while the generation of a significant amount of abraded fines did not affect it, nor did the load level.
\end{abstract}

KEYWORDS: friction; laboratory tests; particle-scale behaviour

ICE Publishing: all rights reserved

\section{NOTATION}

$N$ normal force on contact

$R_{\mathrm{q}} \quad$ root mean square roughness

$T$ shear force on contact

$\mu$ coefficient of friction

\section{INTRODUCTION}

The coefficient of inter-particle friction, $\mu$, is a key parameter in the distinct element method (DEM) analysis of geomaterials and while there has been considerable study on it for natural sands (e.g. Procter \& Barton, 1974; Cole, 2015; Nardelli et al., 2017; Nardelli \& Coop, 2019), there has been much less on crushed rock, such as ballast or rockfill, with limited data in for example Cole (2015) and Tapias et al. (2015) and no comprehensive investigation of what influences it. It might be expected that the behaviour would be very different to that of natural sands, due to the larger size and irregular morphology created by the crushing process. This paper presents a detailed investigation of the factors affecting $\mu$ for a granite ballast. Due to the relatively low number of particles, DEM analyses of railway ballast or rock fill are closer to achieving an accurate $1: 1$ modelling than for sands and analyses using complex shapes are now becoming more common (e.g. Fellerec \& McDowell, 2010; Ahmed et al., 2016). It is therefore no longer adequate to 'calibrate' a model for $\mu$ by curve-fitting macroscale tests such as triaxials, but it needs to be measured.

\section{APPARATUS AND TEST PROCEDURES}

The tests were carried out in a new apparatus (Fig. 1), developed to investigate the contact behaviour of coarsegrained materials. It is described by Wong et al. (2019) and is essentially a scaled-up version of that developed for sands by Senetakis \& Coop (2014) and Nardelli et al. (2017), able to cope with particles up to $50 \mathrm{~mm}$, with vertical and horizontal capacities of 1 and $0.5 \mathrm{kN}$. Two particles are mounted on platens and subjected to loads along three axes that are concentric with their contact. In each axis, the load is applied by a linear actuator and measured with a load cell.

Manuscript received 18 December 2019; first decision 6 October 2020; accepted 12 October 2020.

Published online at www.geotechniqueletters.com on 16 November 2020

*University College London, London, UK.
A key improvement was the use of capacitive non-contact displacement transducers along each axis. The resolution of these transducers is about $10^{-2} \mu \mathrm{m}$ and that of the load cells about $0.01-0.02 \mathrm{~N}$, which is a similar performance to the system of Nardelli et al. even if the load capacity is five times greater, so that the apparatus may even test sand particles. The lower platen is held on a sled, under which is a three-point bearing system, for which the friction was calibrated, even if it was barely significant. Two microscope cameras monitor the test and it is data-logged and controlled by purpose-written software that allows control of each axis in either a force or displacement mode.

To reduce compliance at the contact with the platen, the particles were cut flat on the side opposite the contact tested and then glued to the platens with epoxy resin (Fig. 2), the large flat contact and small thickness of glue ensuring a very small compliance, which was again calibrated. In general, the tests were carried out with a point to flat geometry, as in Fig. 2. Although of course the actual nature of the contact will be complex and dependent on the local morphology, this arrangement was to give a notional single contact. One test was however carried out with a flat to flat particle arrangement and so multiple contacts.

The tests listed in Table 1 were carried out on a typical UK granite ballast, from the Mountsorrel quarry. In each case a vertical load between 20 and $200 \mathrm{~N}$ was applied. The initial contact was made using a slow displacement control to avoid a heavy impact, switching to vertical force control during the test. In one horizontal direction a cyclic displacement of $\pm 1 \mathrm{~mm}$ was applied, while in the other zero displacement was maintained and the perpendicular horizontal forces monitored to ensure that they were not significant. Typically, there were around 1000 cycles, with a period generally of $30 \mathrm{~min}$, giving a duration of about 2-3 weeks. No attempt was made to model the cyclic magnitudes or frequencies that ballast might experience in situ, the purpose of this investigation being to make high-quality measurements of what controls $\mu$. The relatively large cycles ensured that the coefficient of inter-particle friction could be clearly defined on each cycle and that the effects of any local asperities or local contact gradient could be seen. The cycles were also larger than the crystal size of the rock, avoiding the possibility of the data being influenced by contact being made at a specific mineral. In each case, the lower particle being quite flat meant that the vertical displacements during cycling were small relative to the horizontal and so the corrected forces normal and tangential to the surface 


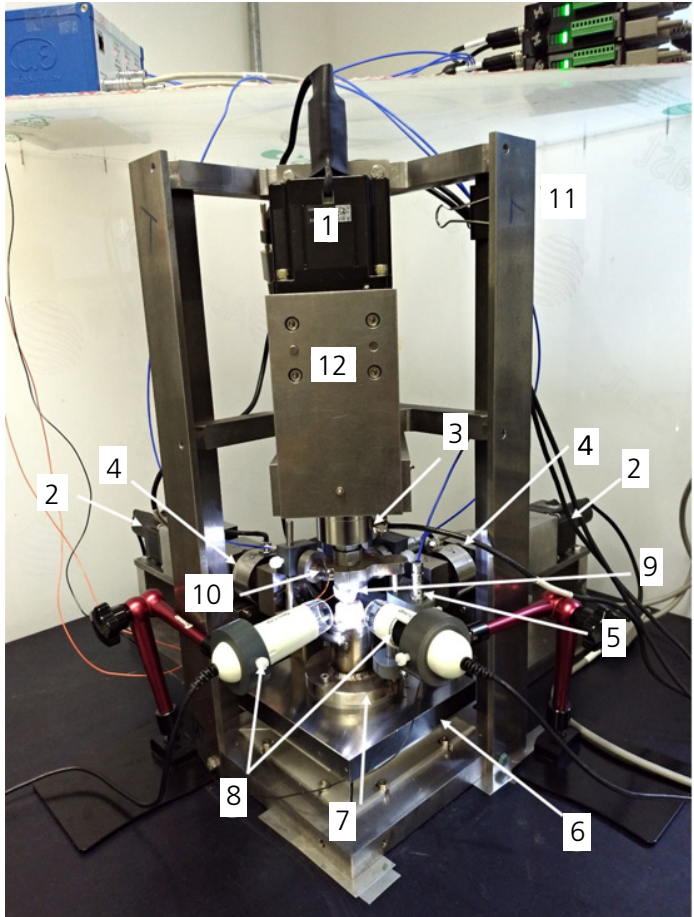

Fig. 1. The new inter-particle loading apparatus: (1) Vertical linear actuator; (2) horizontal linear actuators; (3) vertical load cell; (4) horizontal load cells; (5) vertical displacement transducer; (6) sled; (7) bottom platen; (8) digital microscope; (9) top platen; (10) horizontal displacement transducer; (11) stainlesssteel frame and (12) front plate

were much closer to the applied vertical and horizontal forces than for the small spherical particles and large displacements used by Cavarretta et al. (2010).

\section{EFFECT OF NUMBER OF CYCLES AND WATER FLOODING}

Figure 3 shows a typical test, plotting the ratio of the shear load $T$ to the normal load $N$ against the displacement. The line depicting the data is shaded from dark at the start of the test to light at the end. Generally, the reverse and forward cycles are the mirror image of each other, although there are a few jumps at the start of the reverse cycles that indicate some poorer control of the test around some local asperities. The value of $\mu$, which is the value of $T / N$ at sliding failure, varies a little across the $2 \mathrm{~mm}$ shearing path, probably as a result of local morphology. For this test $\mu$ also increased towards the end of the test as the initially flooded interface was dried, as will be discussed later. The stiffness at the load reversals does not appear to change significantly during the test.

Plotting the values of $\mu$ against the logarithm of the number of cycles in Fig. 4 highlights an increase for most tests, although there is generally a tendency towards more stable values after a few tens of cycles. The increase was unexpected as it was thought beforehand that $\mu$ might reduce as the interface was worn smoother, since Nardelli \& Coop (2019) had demonstrated a clear relationship between inter-particle coefficient of friction and particle roughness for sands of a variety of mineralogies. However, the source of inter-particle friction as measured in macroscopic tests like these is complex. Amonton-Coulomb friction, in which the coefficient of friction would be independent of the true contact area is unlikely to be correct and the macro-scale friction is likely to result from a combination of molecular scale friction and adhesion, for which the true contact area would be important. So while Hanaor et al. (2013) found that simulated fractal surfaces would give higher friction for rougher surfaces, their tests in which fractal surfaces of aluminium were subjected to plastic deformation of the asperities through normal loading found the macro-scale coefficient of friction actually increased as the roughness reduced, which is not dissimilar to what is seen here, although here the roughness change is through wear in shear not plastic deformation of asperities in normal loading.

In Fig. 4 the mean $\mu$ value is plotted, considering the central $1 \mathrm{~mm}$ of the cycle and for most tests taking an average of the forward and reverse data. The cycle extremities were disregarded because in some tests there was a tendency for the abrasion to wear a hole in the lower contact, so that the resistance started to show a pronounced peak just before reversal. The $\mu$ values on the first cycle are quite scattered, from around $0 \cdot 48$ to $0 \cdot 71$, very much higher than the values of $0 \cdot 17-0 \cdot 39$ measured for monotonic shearing of a variety of sand mineralogies by Nardelli \& Coop (2019). For crushed gneiss, which is another crystalline rock, Cole (2015) obtained very scattered values between $0 \cdot 1$ and $0 \cdot 8$, for monotonic shearing, but at much lower load levels of less than $10 \mathrm{~N}$, while Cole et al. (2010) found values of $0.2-0.28$ for smooth contacts of the same rock. Neglecting the water flooded samples highlighted with blue lines, the data tend to converge a little in the first few cycles and then diverge again a little after about 50 cycles, the final values
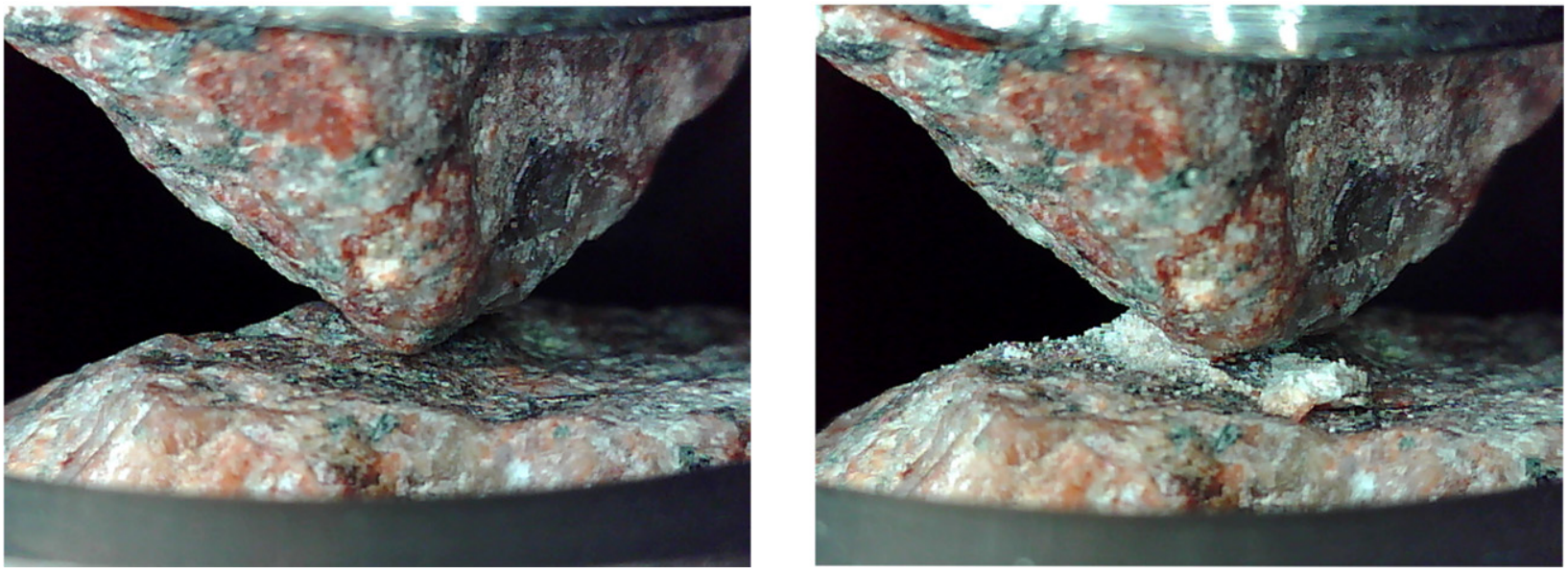

Fig. 2. A typical pair of particles before (left) and after (right) cyclic shearing 
Table 1. Details of the tests (all tests fresh-fresh contacts unless otherwise stated)

\begin{tabular}{|c|c|c|c|}
\hline Test & Loading contact & Vertical load: N & Notes \\
\hline $\mathrm{MC}$ & Multiple contact & 100 & Powder left \\
\hline $\mathrm{SC} 01$ & & 100 & Powder left \\
\hline SC02_a & Old-fresh & 100 & Powder left \\
\hline SC02_b & Old-old & 100 & $\begin{array}{l}\text { Powder removed before testing, powder } \\
\text { left during testing }\end{array}$ \\
\hline $\mathrm{SC} 03$ & Old-old & 20 & Powder left \\
\hline $\mathrm{SC} 04$ & & 20 & Powder left \\
\hline $\mathrm{SC} 05$ & & 20 & Contact cleaned during test \\
\hline $\mathrm{SC} 06$ & & 20 & Contact cleaned during test \\
\hline $\mathrm{SC} 07$ & & 200 & Powder left \\
\hline $\mathrm{SC} 08$ & & 100 & Powder left \\
\hline SC09 & Started dry, flooded after 43 cycles & 200 & Powder left \\
\hline SC10 & Old-fresh. Started dry, flooded after 37 cycles & 200 & Powder left \\
\hline SC11 & Started flooded, dried after 43 cycles & 100 & Powder left \\
\hline $\mathrm{SC} 12$ & Flooded & 20 & Powder left \\
\hline SC13_b & Old-fresh & 100 & Powder left \\
\hline SC14_b & & 200 & Powder left \\
\hline
\end{tabular}

being in the range $0 \cdot 62-0 \cdot 85$ for the dry samples (in grey). Another interesting feature of the data is that the rate of increase of $\mu$ is similar, no matter what the load level.

In some tests the contact was flooded by filling a water bath around the particles, but with no attempt to clean the interface. Test SC12 was flooded throughout, while in tests SC09 and SC10 the flooding was at 43 and 37 cycles, respectively (the line shade changes from grey to blue). Test SC11 started flooding and then was dried at 43 cycles. The effect of water was not apparent in the initial $\mu$ values of $\mathrm{SC} 11$ and SC12, but it is clear that as the cycles proceed the water-flooded samples develop lower values that even tend to decrease rather than increase as the cycles continue. For tests $\mathrm{SC} 09$ and $\mathrm{SC} 10$ the adoption of the saturated $\mu$ is immediate on flooding, while SC11 shows an immediate increase on drying. These data are therefore in contrast to those of Nardelli \& Coop (2019) for various natural sands, for which only very small effects of flooding could be detected. The difference might arise from the much rougher interfaces of the ballast and/or the fact that for these cyclic tests on ballast significant abrasion occurred so the interface is likely to be contaminated with the fine powder that results, while for the monotonic shearing tests on sands of Nardelli $\&$ Coop there was no visible damage.

\section{INFLUENCE OF LOAD LEVEL AND NATURE OF THE INTERFACE}

The normal load levels were chosen on the basis of typical contact forces in DEM analyses of triaxial tests on ballast at the low stress levels characteristic in rail track (McDowell, private communication, 2019). In Fig. 5, the data for dry tests have been identified by load level and in Fig. 6, the $\mu$ values are plotted against the normal load, choosing the mean values after the first 20 cycles. In Fig. 6 for tests that were flooded or dried two data points are shown, one for the initial condition and one after the $\mu$ value has stabilised following the flooding or drying event. Within the data scatter it is difficult to see any significant change of $\mu$ with load level for the dry interfaces. For a natural quartz sand, Nardelli \& Coop (2019) found $\mu$ only to decrease slightly with increasing normal load, from $0 \cdot 20$ over a $0-10 \mathrm{~N}$ range to $0 \cdot 17$ over the range $0-50 \mathrm{~N}$.

Several tests were carried out with one or both surfaces having been used in previous tests (old-fresh or old-old), as highlighted in Figs 6 and 7. These tend to develop $\mu$ more quickly, due to the increase of $\mu$ with the previous cycling. One test (MC) was carried out using surfaces that were nominally flat to flat, to encourage multiple contacts, but

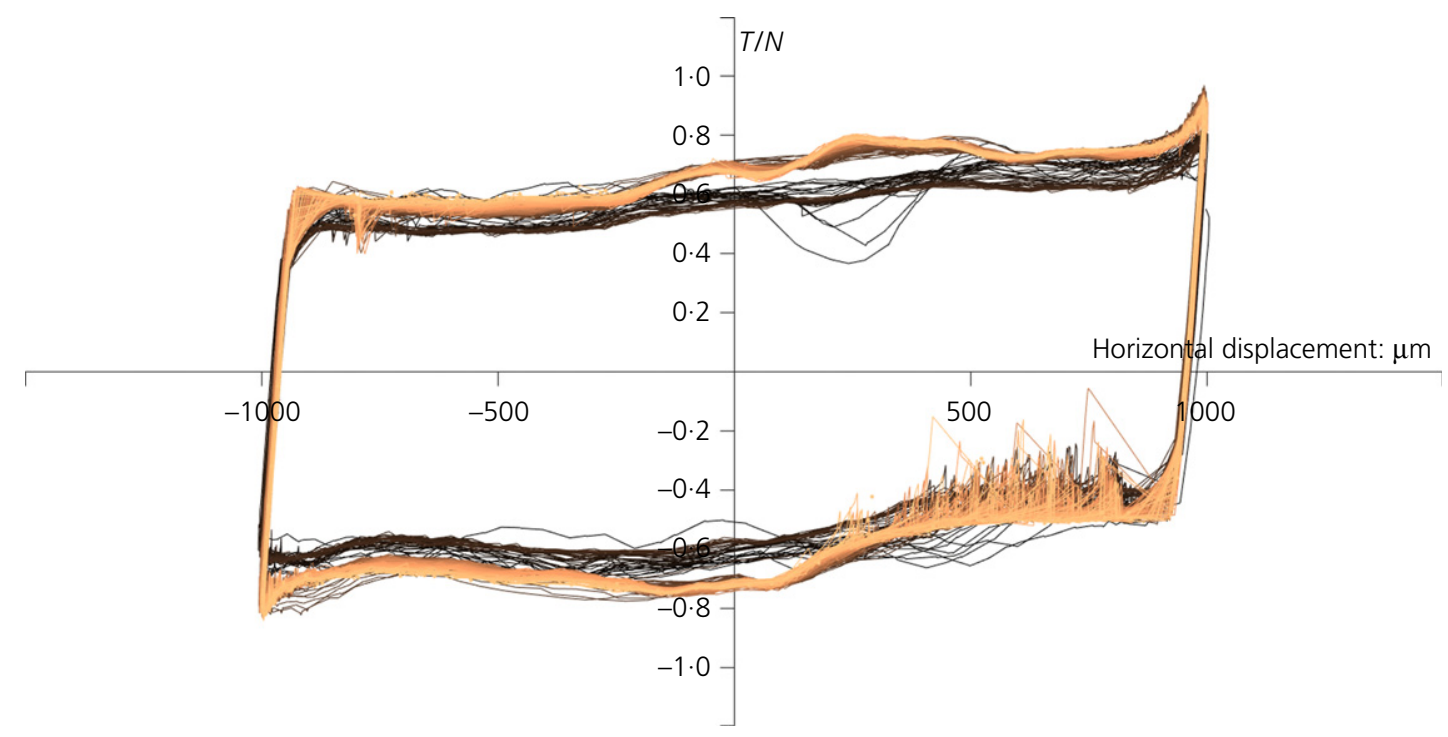

Fig. 3. Typical test data (SC11) (data lines shaded from dark at start of test to light at end) 


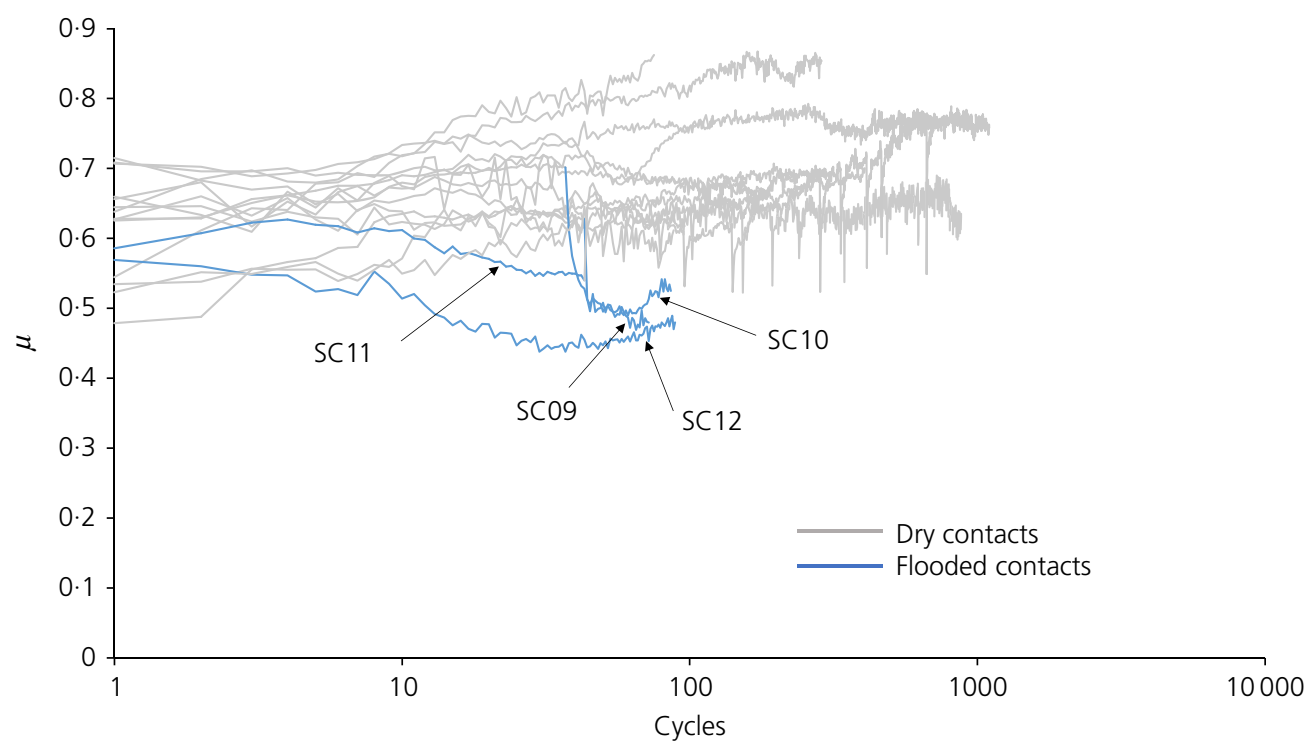

(a)

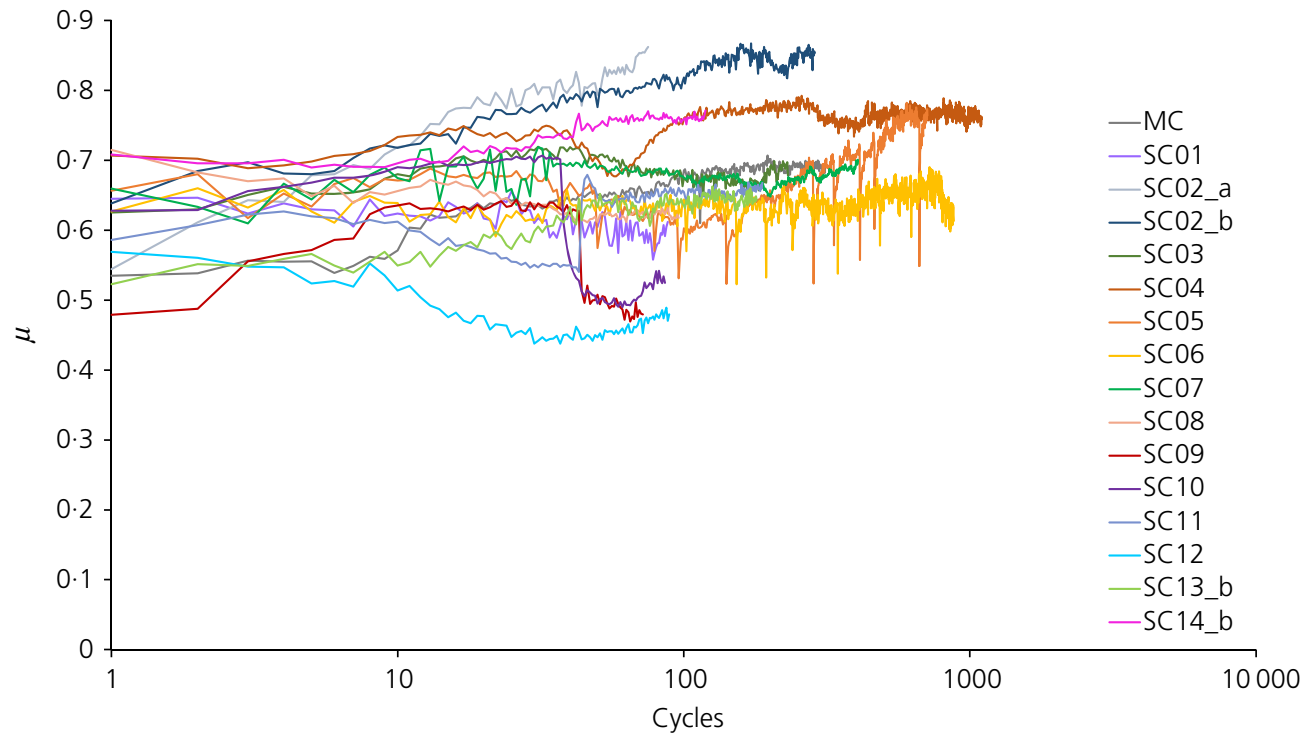

(b)

Fig. 4. The change $\mu$ with continued cyclic loading: (a) highlighting flooded samples; (b) identifying individual tests

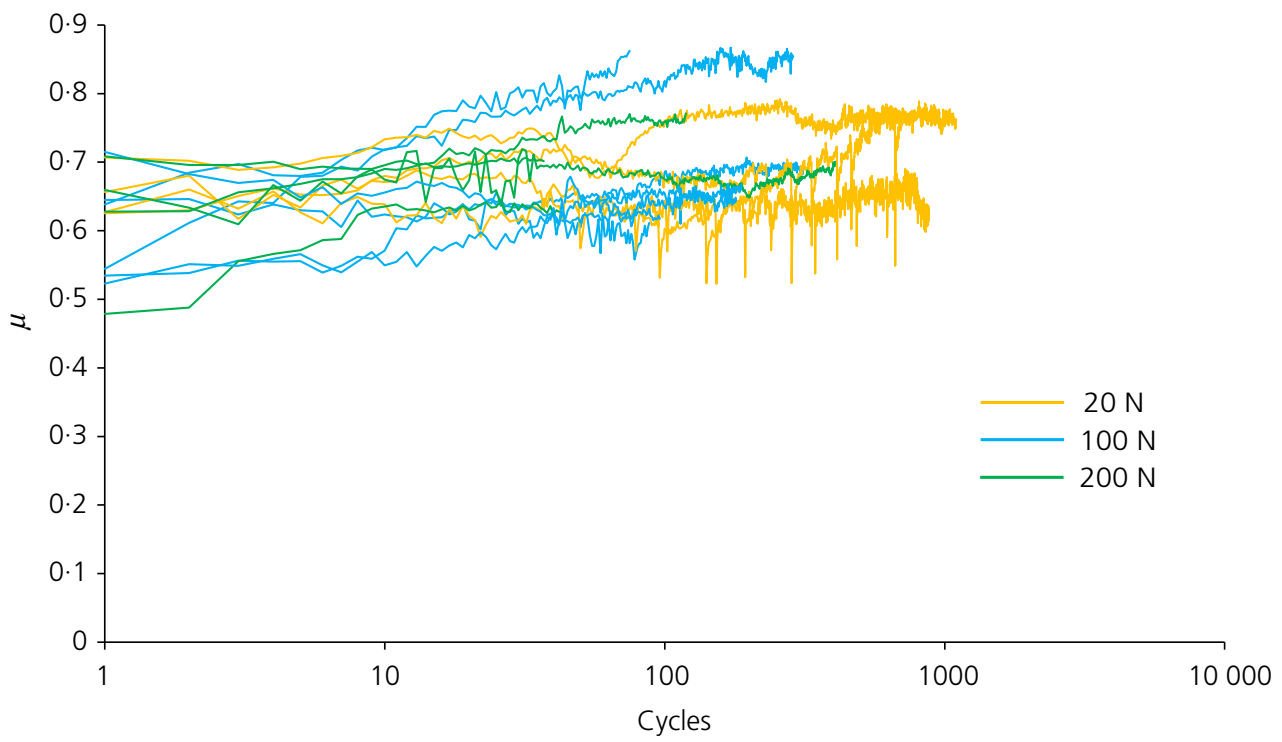

Fig. 5. Influence of load level on the evolution of $\mu$ for tests on dry contacts 


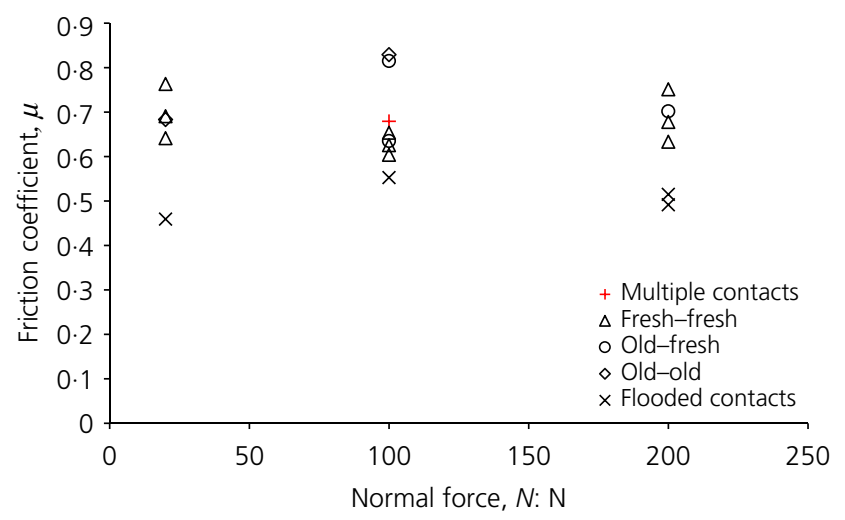

Fig. 6. Effect of normal force, $N$, on values of friction coefficient, $\mu$, measured at 20 cycles although the initial $\mu$ value is lower it quickly converges with those of the other tests.

A key difficulty in testing such irregular particles as ballast is that the contact locations are very difficult to identify even at the visual scale with the views on the two orthogonal microscope cameras generally being partially obscured by surface features. The contact behaviour would depend critically on the true contact area at the asperity scale and Wei et al. (2020) have shown how this depends on the fractal dimension of the roughness as well as the global curvature. Measurements of true contact area have been achieved for regular particles of softer manufactured materials and Weber et al. (2018) have shown how it does not increase linearly with the normal force, while the friction does, giving a non-linear normal force-friction relationship. However, it would be extremely difficult to measure true contact area for the ballast and would require these tests to be carried out in a synchrotron.

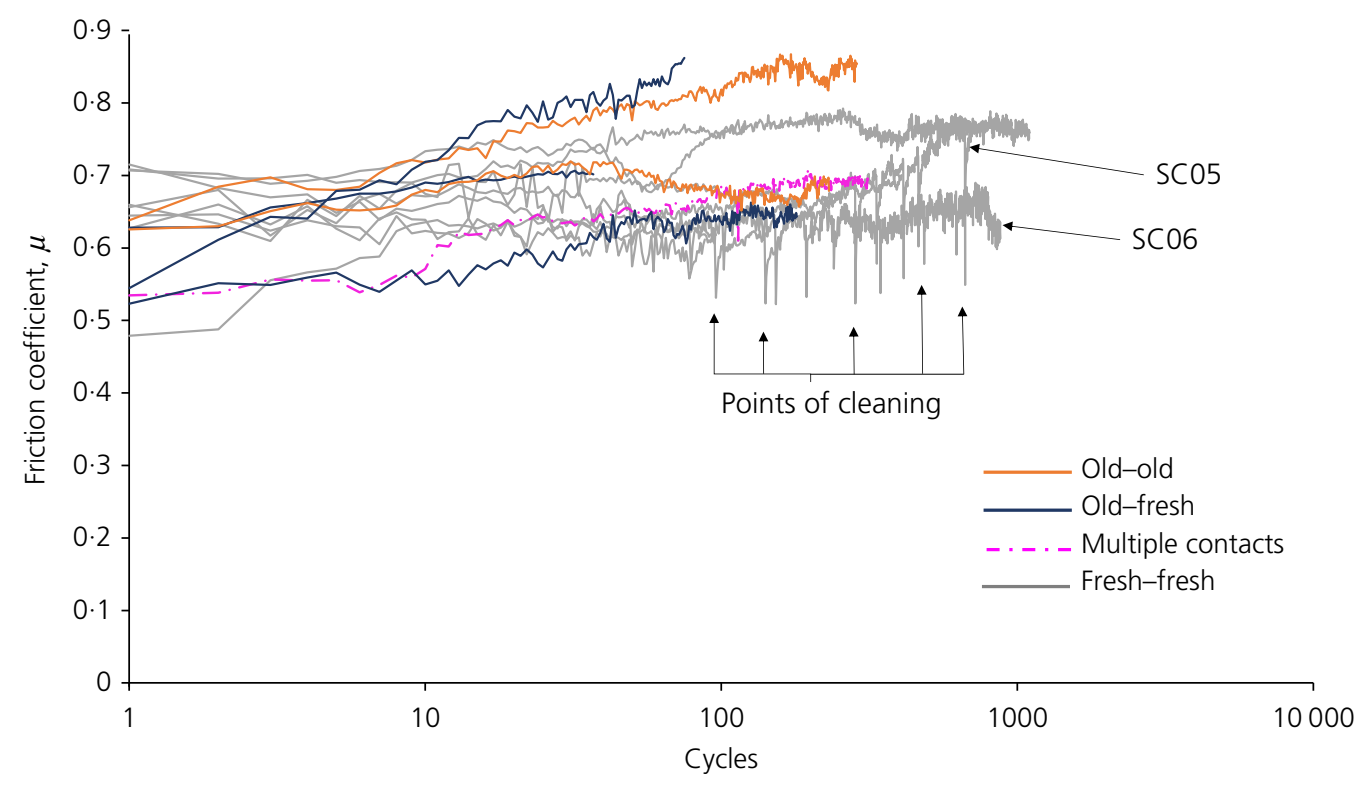

Fig. 7. Tests on pre-sheared interfaces

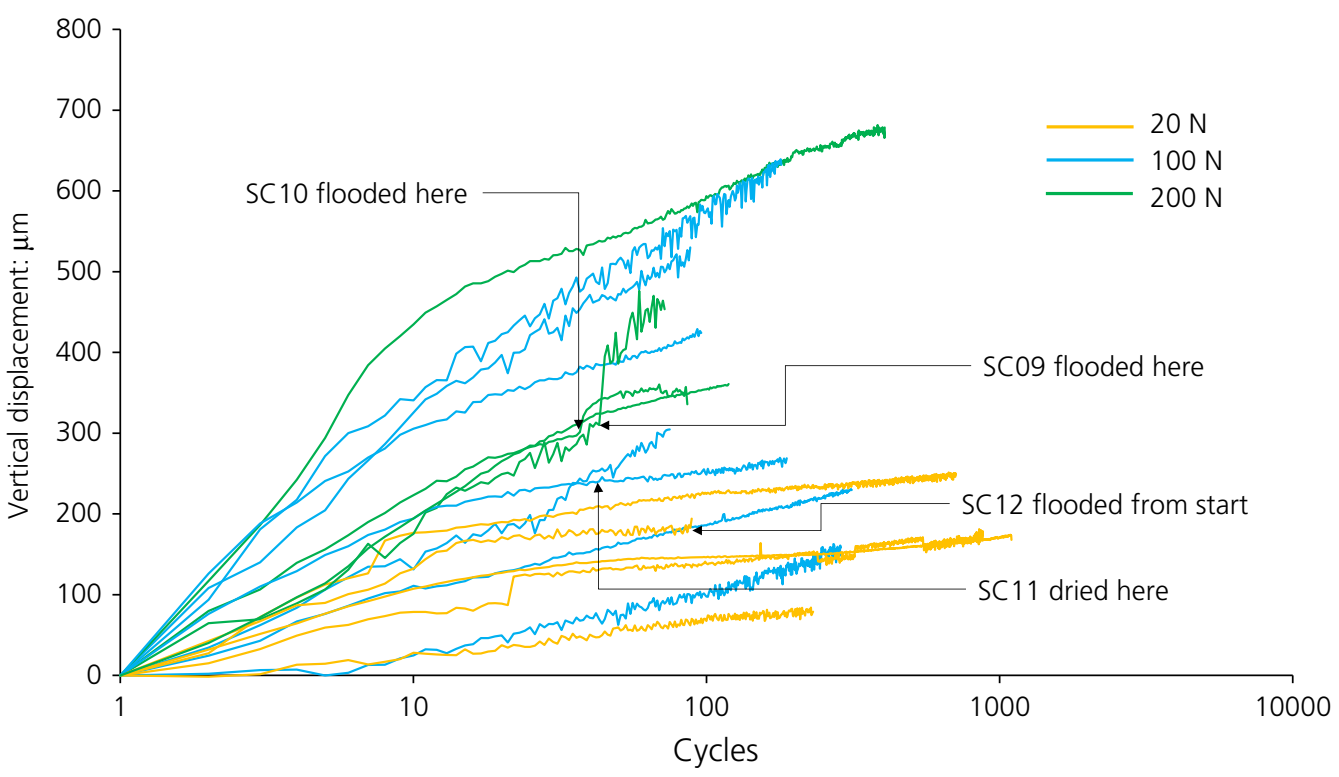

Fig. 8. Vertical displacements of the interface 


\section{ABRASION AT THE INTERFACE}

The cyclic loading generated a significant amount of fines at the interface, as seen in Fig. 2, and this abrasion led to the vertical displacements in Fig. 8, which increased with continued cycling and with load level, and are significant even at the lowest loads. Small increases of displacement are also visible on flooding. Unlike the $\mu$ values the displacements do not stabilise at higher numbers of cycles, although the rate of change of displacement slows. For two tests (SC05 and SC06) the contacts were cleaned as the test continued, by using a damp cotton bud, cleaning the whole contact from $+1 \mathrm{~mm}$ to $-1 \mathrm{~mm}$ over one cycle. Each time the interface was cleaned there was an immediate reduction of $\mu$, some of which are highlighted in Fig. 7. This drop was possibly due to the use of water for cleaning as the $\mu$ value recovered within a few cycles, and the magnitude of the drop was similar to the effects of flooding, although cleaning did not cause a large increase in vertical displacement that flooding did. No flooded test was taken to the same number of cycles as the dry ones, but the values in the cleaning dips allow us to estimate that for wet surfaces $\mu$ might stabilise between about 0.49 and 0.59 . The interfaces that had been cleaned indicate that the presence or absence of the powder does not affect $\mu$, which may be because the powder tended to be pushed outside the contact zone. The mass of powder collected for test SC05 is given in Fig. 9, which also does not stabilise within the number of cycles applied.

The particle size of the powder was derived from a Morphologi particle analyser (Fig. 10). The distribution, based on volume of the particles and using the EQPC diameter (equivalent circle), shows the powder to be mostly between 0.01 and $0.1 \mathrm{~mm}$ and that there were only a few larger particles created; plotting by volume gives emphasis to this small number of larger particles. When laboratory tests are carried out on ballast, the larger scale damage is often quantified, but this powder is generally not measured (e.g. Lackenby et al., 2007).

During the tests, the top, more angular contact tended to become flatter, while a groove was abraded in the lower, as can perhaps be seen in Fig. 2 and might be expected from the displacements in Fig. 8. Images of an upper particle before and after the cyclic shearing are given in Fig. 11, where flattening of the apex is clear. These images were taken using a Z-stack three-dimensional reconstruction on a Zeiss optical microscope. The roughness was measured on a larger magnification image, within the apex area, that had a resolution of $0.65 \mu \mathrm{m}$ and was flattened to remove the form and then the waviness and noise were removed using Gaussian filters. The value of the root mean square

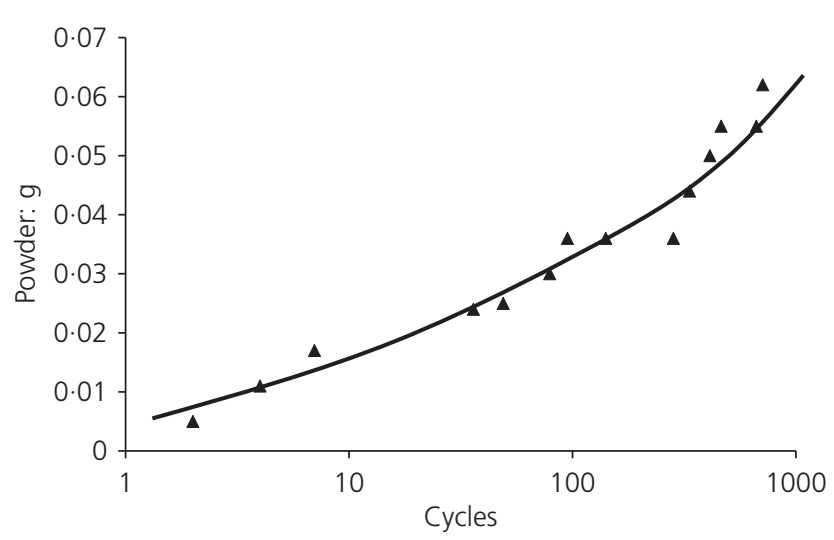

Fig. 9. Mass of abraded powder (test SC05)

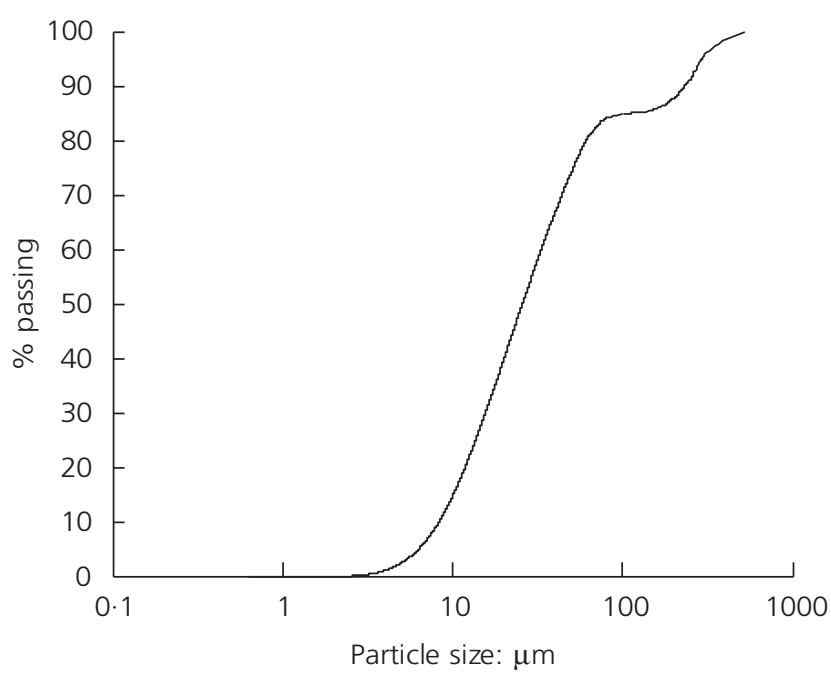

Fig. 10. Particle-size distribution of the abraded powder

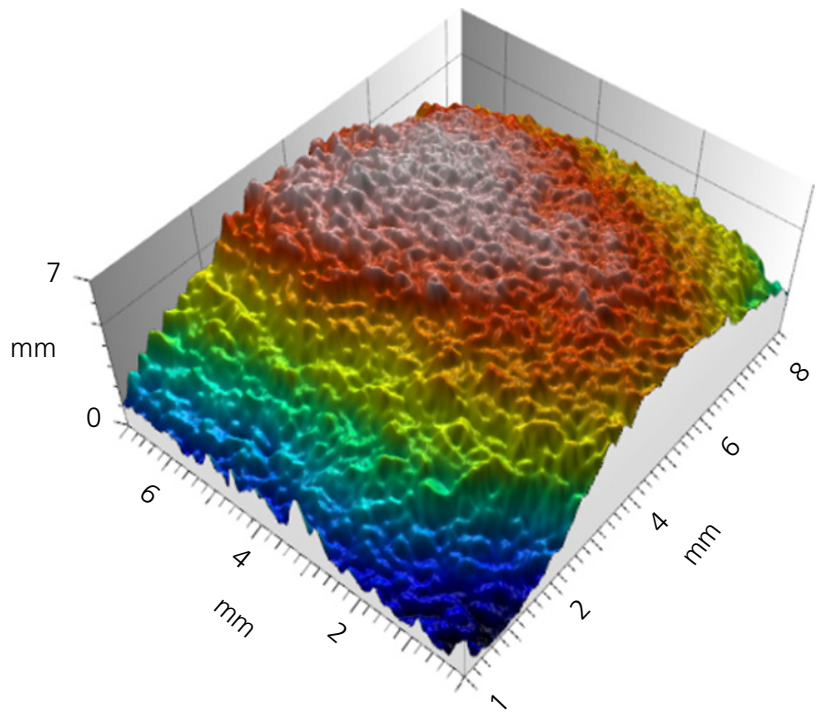

(a)

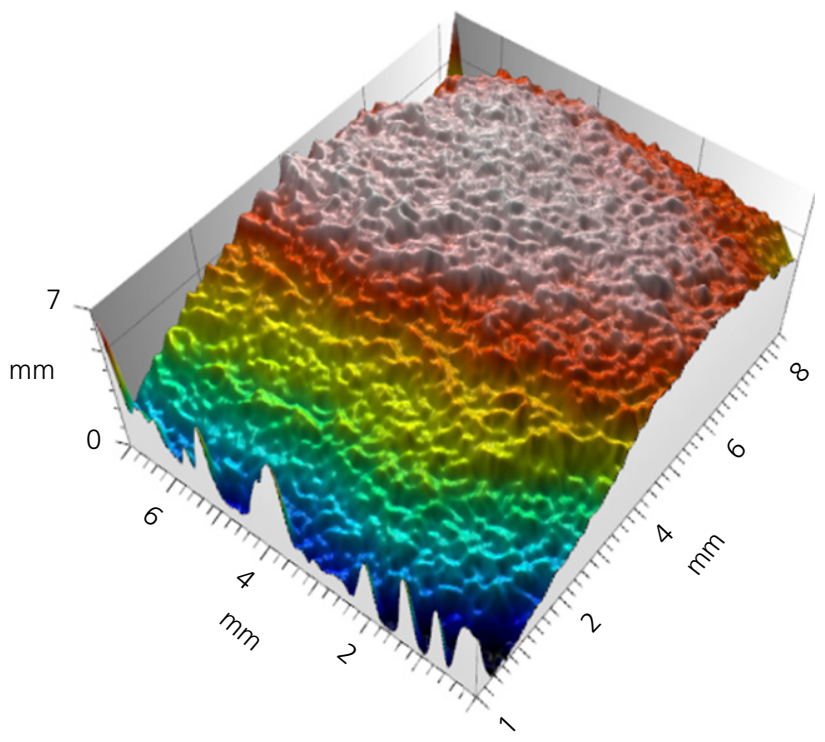

(b)

Fig. 11. Upper particle of test SC11 (a) before cyclic loading and (b) after 
roughness, $R_{\mathrm{q}}$, reduced during the test from 17 to $8 \mu \mathrm{m}$. This was typical for all tests and while it was expected from the abrasion it seems not to agree with the increasing $\mu$, especially considering that Nardelli \& Coop (2019) had found a clear correlation between $\mu$ and $S_{\mathrm{q}}$ for various sands. Zhai et al. (2016) found that contact behaviour depended more on the fractal dimension of the surface than a simple $R_{\mathrm{q}}$, but a box-counting fractal analysis did not show any significant change comparing before and after the tests.

For the ballast, $\mu$ therefore increases while the apparent area of contact increases but roughness reduces. An increase of $\mu$ with roughness is expected for a Coulomb type of friction model (e.g. Bowden \& Tabor, 1950) but the opposite can occur for an adhesive model, often used for non-metallic surfaces (e.g. Ogilvy, 1993). For granite rock interfaces, Engelder (1978) found that the value of $\mu$ for monotonic loading was highly dependent on the asperity size, with values between about $0 \cdot 18$ and $0 \cdot 66$, much more variable than found for these granite ballast contacts. However, the asperity sizes between 0.3 and $2.6 \mu \mathrm{m}$ were much smaller than the roughness measured here. As damage occurred by slipping, the $\mu$ of the rougher surfaces decreased, while those of the smooth surfaces increased, converging at $0 \cdot 5-0 \cdot 6$, somewhat lower than that observed here.

\section{CONCLUSIONS}

Cyclic shearing tests on ballast particle interfaces gave the perhaps surprising result that the interface friction coefficient $\mu$ increased with cycling, while the interface roughness reduced. A significant amount of abraded fines was created and this led to relatively large normal displacements. Load level had no significant effect on $\mu$ and in contrast to previous work on natural sand particles, $\mu$ was significantly reduced by water inundation, with possibly significant implications for the performance of ballasts in situ that will undergo wetting and drying cycles.

\section{ACKNOWLEDGEMENTS}

The authors thank Professor G. R. McDowell and Dr B. A. Baudet for their kind advice and Dr F. Altuhafi for the particle imaging. This research study was funded by the Engineering and Physical Sciences Research Council research grant EP/S026460/1 in collaboration with Professor G. R. McDowell at Nottingham University and Dr. A. Zervos at Southampton University.

\section{DATA ACCESSIBILITY}

The data in this paper may be accessed from http://discovery. ucl.ac.uk or directly from the authors.

\section{REFERENCES}

Ahmed, S., Harkness, J., Le Pen, L., Powrie, W. \& Zervos, A. (2016). Numerical modelling of railway ballast at the particle contact scale. Int. J. Num. Anal. Meth. Geomech. 40, No. 5, 713-737.

Bowden, F. P. \& Tabor, D. (1950). The friction and lubrication of solids. Part 1. Oxford University Press, Oxford, UK.

Cavarretta, I., Coop, M. R. \& O'Sullivan, C. (2010). The influence of particle characteristics on the behaviour of coarse grained soils. Géotechnique 60, No. 6, 413-423, https://doi.org/10.1680/ geot.2010.60.6.413.

Cole, D. M. (2015). Laboratory observations of frictional sliding of individual contacts in geologic materials. Granul. Matter 17, No. 1, 95-110.

Cole, D. M., Mathisen, L. U., Hopkins, M. A. \& Knapp, B. R. (2010). Normal and sliding contact experiments on gneiss. Granul. Matter 12, No. 1, 69-86.

Engelder, T. (1978). Aspects of asperity-surface interaction and surface damage of rocks during experimental frictional sliding. Pure Appl. Geophys. 116, No. 4-5, 705-716.

Fellerec, J. \& McDowell, G. (2010). Modelling realistic shape and particle inertia in DEM. Géotechnique 60, No. 3, 227-232, https://doi.org/10.1680/geot.9.T.015.

Hanaor, D. A., Gan, Y. \& Einav, I. (2013). Effects of surface structure deformation on static friction at fractal interfaces. Géotech. Lett. 3, No. 2, 52-58.

Lackenby, J., Indraratna, B., McDowell, G. \& Chistie, D. (2007). Effect of confining pressure on ballast degradation and deformation under cyclic triaxial loading. Géotechnique 57, No. 6, 527-536, https://doi.org/10.1680/geot.2007.57.6.527.

Nardelli, V., Coop, M. R., Andrade, J. E. \& Paccagnella, F. (2017). An experimental investigation of the micromechanics of Eglin sand. Powder Technol. 312, 166-174.

Nardelli, V. \& Coop, M. R. (2019). The experimental contact behaviour of natural sands: normal and tangential loading. Géotechnique 69, No. 8, 672-686, https://doi.org/10.1680/jgeot. 17.P.167.

Ogilvy, J. A. (1993). Predicting the friction and durability of $\mathrm{MoS}_{2}$ coatings using a numerical contact model. Wear 160, No. 1, 171-180.

Procter, D. C. \& Barton, R. R. (1974). Measurements of the angle of interparticle friction. Géotechnique 24, No. 4, 581-604, https://doi.org/10.1680/geot.1974.24.4.581.

Senetakis, K. \& Coop, M. R. (2014). The development of a new micro-mechanical inter-particle loading apparatus. Geotech. Test. J. 37, No. 6, GTJ20120187, https://doi.org/10.1520/GTJ20120187.

Tapias, M., Alonso, E. E. \& Gili, J. (2015). A particle model for rockfill behaviour. Géotechnique 65, No. 12, 975-994, https://doi.org/10.1680/jgeot.14.P.170.

Weber, B., Suhina, T., Junge, T., Pastewka, L., Brouwer, A. M. \& Bonn, D. (2018). Molecular probes reveal deviations from Amontons' law in multi-asperity frictional contacts. Nat. Commun. 9, No. 1, 888.

Wei, D., Zhai, C., Hanaor, D. \& Gan, Y. (2020). Contact behaviour of simulated rough spheres generated with spherical harmonics. Int. J. Solids Struct. 193, 54-68.

Wong, C. P. Y., Boorman, B. \& Coop, M. R. (2019). The construction and commissioning of a new inter-particle loading apparatus for the micromechanical behaviour of railway ballast. Proceedings of IS Atlanta 2018 symposium on geomechanics from micro to macro in research and practice, Atlanta, USA.

Zhai, C., Gan, Y., Hanaor, D., Proust, G. \& Retraint, D. (2016). The role of surface structure in normal contact stiffness. Exp. Mech. 56, No. 3, 359-368.

\section{HOW CAN YOU CONTRIBUTE?}

To discuss this paper, please submit up to 500 words to the editor at journals@ice.org.uk. Your contribution will be forwarded to the author(s) for a reply and, if considered appropriate by the editorial board, it will be published as a discussion in a future issue of the journal. 